TITLE:

\title{
Fabrication of carbon nanotube/NiOx(OH)y nanocomposite by pulsed electrodeposition for supercapacitor applications
}

\section{AUTHOR(S):}

Hakamada, Masataka; Moriguchi, Akitoshi; Mabuchi, Mamoru

\section{CITATION:}

Hakamada, Masataka ...[et al]. Fabrication of carbon nanotube/NiOx(OH)y

nanocomposite by pulsed electrodeposition for supercapacitor applications. Journal of Power Sources 2014, 245: 324-330

\section{ISSUE DATE:}

2014-01

URL:

http://hdl.handle.net/2433/176997

\section{RIGHT:}

C 2013 Elsevier B.V.; この論文は出版社版でありません。引用の際には 出版社版をご確認ご利用ください。; This is not the published version. Please cite only the published version. 


\title{
Fabrication of carbon nanotube $/ \mathrm{NiO}_{x}(\mathrm{OH})_{y}$ nanocomposite by pulsed electrodeposition for supercapacitor applications
}

\author{
Masataka HAKAMADA*, Akitoshi MORIGUCHI, Mamoru MABUCHI \\ Department of Energy Science and Technology, Graduate School of Energy Science, \\ Kyoto University, Yoshidahonmachi, Sakyo, Kyoto 606-8501, Japan \\ * Corresponding author. Tel: +81-75-753-5427; fax: +81-75-753-5428. E-mail: \\ hakamada.masataka.3x@kyoto-u.ac.jp (M. Hakamada). \\ Abstract
}

Nanocomposite films based on carbon nanotubes (CNTs)/ nickel (Ni)-species were fabricated by electrophoretic deposition (EPD) of CNT, followed by pulsed electrodeposition of $\mathrm{Ni}$ and annealing in air. $\mathrm{NiO} / \mathrm{Ni}(\mathrm{OH})_{2}$ particles with $7 \pm 4 \mathrm{~nm}$ diameters were uniformly dispersed on the CNT networks. Cyclic voltammetry revealed that the $\mathrm{CNT} / \mathrm{NiO}_{x}(\mathrm{OH})_{y}$ nanocomposite films had high specific capacitances of 1451 , $1158,998,896$ and $851 \mathrm{~F} / \mathrm{g}$ per mass of active Ni species at 1, 10, 30, 50 and $100 \mathrm{mV} / \mathrm{s}$, respectively, in the potential window of $0.4 \mathrm{~V}$. An annealing time of $1 \mathrm{~h}$ (at $523 \mathrm{~K}$ ) enhanced the pseudocapacity of deposited $\mathrm{Ni}$ species by the dehydration of $\mathrm{Ni}(\mathrm{OH})_{2}$ to form NiO. Longer annealing time reduced the capacitance because of sintering and subsequent decrease in surface area of Ni deposits. The capacitance of the fabricated $\mathrm{CNT} / \mathrm{NiO}_{x}(\mathrm{OH})_{y}$ nanocomposite was maintained after 20000 cycles of potential sweeping.

Keywords: carbon nanotube; nickel oxide; nanocomposite; pulsed electrodeposition; pseudocapacitance 


\section{Introduction}

First reported by Iijima [1], carbon nanotubes (CNTs) have drawn considerable attention in material sciences. Multi-walled CNTs form three-dimensional networks and are frequently used as thin films in applications such as capacitors, actuators and displays [2]. Electrophoretic deposition (EPD) can be used to fabricate CNT into films with micrometer-scale thickness [3]. Thin films of CNTs are good candidates for high surface area support materials. In addition, the high electrical conductivity of multi-walled CNTs distinguishes them from other porous supports such as mesoporous silica and titania.

Nanocomposites of $\mathrm{CNT}$ and $\mathrm{Ni}$ species are promising for applications in capacitors [4], hydrogen storage [5,6] and hydrogenation catalysis [7]. In particular, CNT/NiO or $\mathrm{CNT} / \mathrm{Ni}(\mathrm{OH})_{2}$ nanocomposites show potential for applications in capacitors [8-19]. Capacitors are energy storage devices that may be become a backup power source for hybrid vehicles. Compared with batteries, capacitors generally feature lower energy densities but greater cycling capacity [20]. Energy density is represented by $1 / 2 C V^{2}$, where $C$ is capacitance and $V$ is voltage between the two electrodes [20]. Current challenges in capacitor development are the simultaneous achievement of high capacitance and voltage windows. Recently, metal oxides such as $\mathrm{NiO}$ [8-19], $\mathrm{RuO}_{2}$ [21,22] and $\mathrm{MnO}_{2}$ [23] have received attention as promising materials for a type of pseudocapacitors. These pseudocapacitors use a redox reaction at the surface of the oxides for energy storage. The theoretical capacitances of $\mathrm{NiO}$ and $\mathrm{Ni}(\mathrm{OH})_{2}$ are 2584 F/g and $2082 \mathrm{~F} / \mathrm{g}$ within $0.5 \mathrm{~V}$ [14,24].

CNT/Ni-species (including $\mathrm{Ni}, \mathrm{NiO}, \mathrm{Ni}(\mathrm{OH})_{2}$ ) nanocomposites may be effectively fabricated by electroless plating [4-7], electroplating [8,10-12,15,25,26], impregnation 
$[27,28]$ and other processes $[9,16,18]$. Pulsed electrodeposition, in which the applied potential is oscillated at high frequencies during deposition of metals, is another strategy to fabricate nanostructured $\mathrm{Ni}[29,30]$. In this study, we carried out pulsed electrodeposition of $\mathrm{Ni}$ on CNTs and annealing in air to make a $\mathrm{CNT} / \mathrm{NiO}_{x}(\mathrm{OH})_{y}$ nanocomposite. We investigated capacitive properties of the $\mathrm{CNT} / \mathrm{NiO}_{x}(\mathrm{OH})_{y}$ by cyclic voltammetry (CV) and chronopotentiometry (CP).

\section{Experimental}

Commercially available multi-walled CNTs (FloTube 9000, prepared by a catalytic vapor deposition process) were purchased from CNano Technology Ltd (Santa Clara, US). The raw CNTs were first treated in a concentrated mixture of $15.6 \mathrm{~mol} / \mathrm{L}$ nitric acid and $18 \mathrm{~mol} / \mathrm{L}$ sulfuric acid (with volumetric ratio of $1: 3$ ) at $333 \mathrm{~K}$ for $8 \mathrm{~h}$. The treated CNTs were then washed several times by ultrasonication in distilled water to remove excess acid.

Following the acid treatment, EPD was carried out to fabricate the CNT film. The negative and positive electrodes were Pt and SUS316L (The Nilaco Corp., Tokyo, Japan) foils with exposed areas of $20 \times 25 \mathrm{~mm}^{2}$ and thickness of $20 \mu \mathrm{m}$, respectively. The distance between the electrodes was $20 \mathrm{~mm}$. The acid-treated CNTs were suspended at a concentration of $1 \mathrm{~g} / \mathrm{L}$ in distilled water for EPD. A voltage of $30 \mathrm{~V}$ was applied between the electrodes at room temperature (298 K) for 90 s. After the EPD, the CNTs film was dried in air and then heated at $673 \mathrm{~K}$ for $3 \mathrm{~h}$ to oxidize and insulate the SUS316L substrate. This oxidation step facilitated preferential electrodeposition of Ni on CNTs rather than the SUS316L substrate. Pulsed electrodeposition of Ni was carried out on the CNTs film to form CNTs/Ni nanocomposite film. The pulsed current is 
shown in Fig. S1 (in Supplementary Data) with maximum current densities of 3 and $0.03 \mathrm{~A} / \mathrm{cm}^{2}$ applied for 0.5 and $50 \mathrm{~s}$, respectively. These current densities were calculated from division of the current by the apparent exposed area $\left(5 \mathrm{~cm}^{2}\right)$. The electrolyte was composed of $\mathrm{NiSO}_{4} \cdot 6 \mathrm{H}_{2} \mathrm{O}(240 \mathrm{~g} / \mathrm{L}), \mathrm{NiCl}_{2} \cdot 6 \mathrm{H}_{2} \mathrm{O}(45 \mathrm{~g} / \mathrm{L}), \mathrm{H}_{3} \mathrm{BO}_{3}(35$ $\mathrm{g} / \mathrm{L}$ ) and $\mathrm{C}_{7} \mathrm{H}_{5} \mathrm{NO}_{3} \mathrm{~S}$ (saccharin, $2.4 \mathrm{~g} / \mathrm{L}$ ). The CNTs substrate made up the cathode and Ni plate (The Nilaco Corp., Japan) was used for the anode. The temperature was maintained at $323 \mathrm{~K}$ during the pulsed electrodeposition. After electrodeposition, the CNTs/Ni nanocomposite film was washed with distilled water several times and dried in air. Several samples were annealed in air to oxidize $\mathrm{Ni}$, at temperatures of 473,523 or $573 \mathrm{~K}$ for durations of 1 and $72 \mathrm{~h}$.

The samples were observed by a scanning electron microscope (SEM, SU-6600 by Hitachi High-Technologies Corporation, Japan) equipped with an energy-dispersive X-ray (EDX) spectrometer. X-ray photoelectron spectra (XPS) of the samples were also collected under vacuum $\left(6.7 \times 10^{-8} \mathrm{~Pa}\right)$ using ESCA5800 (ULVAC-PHI, Inc., Chigasaki, Japan) with $\mathrm{Al} \mathrm{K \alpha}$ radiation $(h v=1486.6 \mathrm{eV})$. X-ray diffraction (XRD) analyses were also conducted by using X'Pert Pro by PANalytical, operated under a glancing beam configuration $\left(0.5^{\circ}\right)$ with $\mathrm{Cu}$ radiation.

Cyclic voltammetry (CV) and chronopotentiometry (CP) were conducted using a potentiostat and charge-discharge tester, respectively. A typical three-electrode electrochemical cell with a Pt black counter electrode, a saturated calomel electrode (SCE) reference electrode and the CNTs/Ni sample were used as the working electrode. The electrolyte was an aqueous $\mathrm{KOH}$ s solution $(6 \mathrm{~mol} / \mathrm{L}) . \mathrm{CV}$ was performed at 1,10 , $30,50,100 \mathrm{mV} / \mathrm{s}$ in a potential range of -0.05 to $+0.35 \mathrm{~V}$ (in this article, potentials are documented vs SCE unless otherwise stated). CP was performed at $1 \mathrm{~mA}(5.6 \mathrm{~A} / \mathrm{g}), 5$ 
$\mathrm{mA}(27.8 \mathrm{~A} / \mathrm{g}), 25 \mathrm{~mA}(138.9 \mathrm{~A} / \mathrm{g})$ in a potential range of -0.05 to $+0.35 \mathrm{~V}$. Before the capacitance measurements, the mass of the $\mathrm{CNT} / \mathrm{NiO}_{x}(\mathrm{OH})_{y}$ composite electrode was measured by electronic balance (Shimadzu AUW-220D). After the capacitance measurements, the composite layer (exposed to the electrolyte) were manually detached from SUS316 substrate and the mass of the electrode without the composite was measured. The difference between the mass values of the sample before and after the detaching was adopted as the real composite mass. EDX was used to know the elemental composition of the composite.

\section{Results}

\subsection{SEM characterization}

Figure 1a shows a surface view of CNTs film (after EPD and before Ni electrodeposition). CNTs with average diameter of $13 \mathrm{~nm}$ formed a nanoporous network. The thickness was approximately $1 \mu \mathrm{m}$, as estimated by optical microscopy. Figure $1 \mathrm{~b}$ shows the CNT/Ni nanocomposite fabricated by pulsed electrodeposition at a low current density of $0.03 \mathrm{~A} / \mathrm{cm}^{2}$. Spherical nanoparticles with a diameter of $50 \pm 20 \mathrm{~nm}$ were deposited on to the CNTs at a current density of $0.03 \mathrm{~A} / \mathrm{cm}^{2}$. Figure $1 \mathrm{c}$ shows the CNT/Ni nanocomposite fabricated by pulsed electrodeposition at a high maximum current density of $3 \mathrm{~A} / \mathrm{cm}^{2}$. Small (diameter of $7 \pm 4 \mathrm{~nm}$, calculated by the SEM image analyses) nanoparticles were deposited on to the CNTs at the high current density of 3 $\mathrm{A} / \mathrm{cm}^{2}$. EDX analyses showed the CNT/Ni contained approximately $35 \%$ by mass of Ni in the nanocomposites fabricated at both high and low current densities.

Previous studies of electrodeposited Ni nanoparticles on CNTs gave Ni particles with diameters larger than $15 \mathrm{~nm}[8,10,25,26]$. In this study, Ni deposits with diameters less 
than $10 \mathrm{~nm}$ were achieved, using pulsed electrodeposition applied at a maximum current density of $3 \mathrm{~A} / \mathrm{cm}^{2}$. This demonstrates that pulsed electrodeposition of $\mathrm{Ni}$ is effective for reducing the size of $\mathrm{Ni}$ deposits on $\mathrm{CNT}$.

Figure 2 shows the SEM images of the $\mathrm{CNT} / \mathrm{NiO}_{x}(\mathrm{OH})_{y}$ nanocomposite fabricated by pulsed electrodeposition of $\mathrm{Ni}$ at $3 \mathrm{~A} / \mathrm{cm}^{2}$ and annealed in air at $523 \mathrm{~K}$ for 1 and $72 \mathrm{~h}$. Comparison of Fig. 2a with that of the sample before annealing (Fig. 1c) revealed that the size and distribution of the deposits on the CNTs were unchanged by the 1-h annealing step. The Ni deposits maintained a fine dispersion during the annealing, suggesting a high surface area was also preserved. However, the 72-h annealed sample (Fig. 2b) showed a change of deposition texture, with deposits showing an average diameter of $15 \mathrm{~nm}$. Sintering of Ni deposits is the likely cause of this change in the texture from 72-h annealing. On the other hand, XRD analyses on the samples showed no crystalline phases for Ni species, as shown in Fig. S2 in the Supplementary Data, suggesting that the $\mathrm{Ni}$ deposits are amorphous even after the annealing. Thus, unfortunately, the $\mathrm{NiO} / \mathrm{Ni}(\mathrm{OH})_{2}$ phase composition is unclear.

\subsection{Electrochemical tests of capacitances}

Figure 3 shows the $\mathrm{CV}$ curves of the $\mathrm{CNT} / \mathrm{NiO}_{x}(\mathrm{OH})_{y}$ nanocomposite fabricated by pulsed electrodeposition at $3 \mathrm{~A} / \mathrm{cm}^{2}$ and annealed in air at $523 \mathrm{~K}$ for $1 \mathrm{~h}$. The $\mathrm{CV}$ curves featured clear redox peak pairs corresponding to the superficial Faradic reactions. The oxidation and reduction peaks were shifted to higher and lower potentials, respectively, with a midpoint potential of $+0.16 \mathrm{~V}$, as the scan rate increased. The symmetry of the CV curves suggested that the redox reactions were highly reversible, suggesting good potential for repeated cycling. The other samples fabricated under various conditions 
also exhibited similar symmetric CV curves with redox peak pairs.

The specific capacitances $(C)$ per mass of nanocomposite (approximately $0.5 \mathrm{mg}$ ) in each sample were determined from the CV curves using the following equation $[14,19]$ : $C=\frac{1}{2 m \Delta V} \int_{V_{\mathrm{i}}}^{V_{\mathrm{f}}} \frac{|I|}{(d V / d t)} d V,(1)$

where $m$ is the mass of nanocomposite, $\Delta V$ is the potential window, $V_{\mathrm{i}}$ and $V_{\mathrm{f}}$ are the starting and ending potentials in one cycle, respectively, $I$ is the instantaneous current at a given potential and $d V / d t$ is the scan rate.

Figure 4 summarizes the relationship between scan rate and specific capacitance per mass of $\mathrm{CNT} / \mathrm{NiO}_{x}(\mathrm{OH})_{y}$ nanocomposite, for samples fabricated under different conditions. Figure $4 \mathrm{a}$ shows specific capacitances of the CNT/Ni nanocomposite fabricated at a maximum current density of 3 and $0.03 \mathrm{~mA} / \mathrm{cm}^{2}$ and annealed in air at $523 \mathrm{~K}$ for $1 \mathrm{~h}$. The specific capacitance of the CNT/Ni nanocomposite fabricated at 3 $\mathrm{A} / \mathrm{cm}^{2}$ was higher than that of the nanocomposite fabricated at $0.03 \mathrm{~mA} / \mathrm{cm}^{2}$. As observed in SEM images (Fig. 1c), Ni deposits on CNT were smaller (7 nm) in the nanocomposite fabricated at $3 \mathrm{~A} / \mathrm{cm}^{2}$. These particles therefore presented a larger surface area of active $\mathrm{Ni}$ than the sample fabricated at $0.03 \mathrm{~A} / \mathrm{cm}^{2}$. These results suggested the redox reactions and capacitive behavior were related to the nature of the Ni deposits.

The CNT/Ni nanocomposites fabricated at $3 \mathrm{~A} / \mathrm{cm}^{2}$ were annealed in air at various temperatures and durations. Figure $4 \mathrm{~b}$ shows the effect of annealing conditions on the specific capacitances of $\mathrm{CNT} / \mathrm{NiO}_{x}(\mathrm{OH})_{y}$ nanocomposites (fabricated at $3 \mathrm{~A} / \mathrm{cm}^{2}$ ). High specific capacitances were obtained under the annealing conditions $(T, t)=(523 \mathrm{~K}, 1 \mathrm{~h})$, $(523 \mathrm{~K}, 72 \mathrm{~h})$ and $(573 \mathrm{~K}, 72 \mathrm{~h})$, where $T$ is the annealing temperature and $t$ is the annealing time. The annealing conditions $(T, t)=(523 \mathrm{~K}, 1 \mathrm{~h})$ gave nanocomposites 
with the highest capacitance at low scan rates. The specific capacitance of the $(T, t)=$ (473 K, $72 \mathrm{~h}$ ) sample was lower than other samples annealed at higher temperature and almost similar to that of the CNT/Ni sample without annealing. Figures $4 \mathrm{c}$ and $4 \mathrm{~d}$ also indicate that the annealing conditions $(T, t)=(523 \mathrm{~K}, 1 \mathrm{~h})$ is the best.

The constant-current electrodeposition of $\mathrm{Ni}$ at $3 \mathrm{~A} / \mathrm{cm}^{2}$ for $0.5 \mathrm{~s}$ on CNTs has been conducted for comparison. Fig. S3 (in Supplementary Data) shows the SEM image of the sample fabricated by the constant-current electrodeposition of $\mathrm{Ni}$ and subsequent annealing at $523 \mathrm{~K}$ for $1 \mathrm{~h}$. Ni-species particles with the average diameter of $40 \mathrm{~nm}$ were deposited on the CNTs. CV measurements revealed that the specific capacitance per mass of composites was $275,172,167,112 \mathrm{~F} / \mathrm{g}$ at the scan rates of 10, 30, 50 and $100 \mathrm{mV} / \mathrm{s}$, respectively. The capacitance was much lower than that of the samples fabricated by the pulsed electrodeposition (Fig. 4). Thus, the advantage of the pulsed electrodeposition is the finer size of $\mathrm{Ni}$ deposits.

Figure 5 shows galvanostatic discharge curves from different discharge currents from the $\mathrm{CNT} / \mathrm{NiO}_{x}(\mathrm{OH})_{y}$ nanocomposite fabricated at $3 \mathrm{~A} / \mathrm{cm}^{2}$ and annealed in air at $523 \mathrm{~K}$ for $1 \mathrm{~h}$. Higher discharge currents gave a shorter discharge time, consistent with previous results $[13,14,16,18]$. From the discharge curves, the specific capacitances $(C)$ per mass of nanocomposite were derived using the following equation [18]:

$C=\frac{I \Delta t}{m \Delta V}$

where $I$ is the discharge current, $\Delta V$ is the potential window, $\Delta t$ is the discharge time in the potential window and $m$ is mass of the nanocomposite. The specific capacitances per mass of nanocomposites were calculated to be $676,490,364 \mathrm{~F} / \mathrm{g}$ at discharge currents of 5.6, 27.8, 138.9 A/g, respectively. The capacitance was higher at smaller discharge currents, in accordance with previous results $[17,18,20,22]$. The capacitances calculated 
from the $\mathrm{CP}$ results were of the same order of those calculated from CV results.

We also performed 20000-cycle CP tests at $138.9 \mathrm{~A} / \mathrm{g}$ of nanocomposite fabricated at maximum current density of $3 \mathrm{~A} / \mathrm{cm}^{2}$ and annealed in air at $523 \mathrm{~K}$ for $1 \mathrm{~h}$. The results are shown in Fig. 6. The specific capacitance generally increased and stabilized after 10000 cycles, although the noticeable decrease and increase in the capacitance was observed at 8000 cycles (at this stage, the reason for the capacitance change at 8000 cycles are not understood). During subsequent cycles, the specific capacitance remained unchanged from the higher value. Charge/discharge curves (shown in the inset) revealed that the time for charge/discharge cycles became longer in the later cycles, owing to the increased capacitance (see Eq. (2)). This increase in capacitance could be explained by removal of contamination such as carbonaceous material and adsorbed gases on the CNT/Ni-species nanocomposites during the first 10000 charge/discharge cycles. These results demonstrated an excellent stability to repeated charge/discharge cycling of the CNT/Ni nanocomposites.

\section{Discussion}

As shown above, $(T, t)=(523 \mathrm{~K}, 1 \mathrm{~h})$ was the best annealing condition. In this section, we focus on the effect of annealing time on the oxidation state and activity of $\mathrm{Ni}$ species, because annealing at $573 \mathrm{~K}$ may damage CNTs and alter the electric properties of not only Ni species but CNTs.

\subsection{Surface states of deposited $\mathrm{Ni}$}

The Faradic reactions of Ni species are described by the following equations [31]:

$$
\begin{aligned}
& \mathrm{NiO}+\mathrm{OH}^{-} \leftrightarrow \mathrm{NiOOH}+\mathrm{e}^{-}(3) \\
& \mathrm{Ni}(\mathrm{OH})_{2}+\mathrm{OH}^{-} \leftrightarrow \mathrm{NiOOH}+\mathrm{H}_{2} \mathrm{O}+\mathrm{e}^{-}(4) .
\end{aligned}
$$


The equilibria between $\mathrm{NiO}$ and $\mathrm{Ni}(\mathrm{OH})_{2}$ determines the electrochemical capacitance. Figure 7 gives the XPS of $\mathrm{CNT} / \mathrm{NiO}_{x}(\mathrm{OH})_{y}$ nanocomposites fabricated by pulsed electrodeposition at $3 \mathrm{~A} / \mathrm{cm}^{2}$ before and after annealing in air at $523 \mathrm{~K}$. Before annealing, the surface of nanocomposite contained a large proportion of $\mathrm{Ni}(\mathrm{OH})_{2}(856.0$ $\mathrm{eV}[32,33]$ for $\mathrm{Ni} 2 \mathrm{p}_{3 / 2}$ and $531.5 \mathrm{eV}[34,35]$ for $\left.\mathrm{O} 1 \mathrm{~s}\right)$ as well as a smaller proportion of metallic Ni (852.8 eV [36]). This suggested that the majority of nanosized Ni deposits (Fig. 1c) were oxidized to form hydroxide during pulsed electrodeposition, water washing and drying in air. However, annealing at $523 \mathrm{~K}$ completely removed the metallic Ni component around $852.8 \mathrm{eV}$. Valence level XPS Spectra around $0 \mathrm{eV}$ (Fig. 7c) also showed a decrease in intensity around $1.0 \mathrm{eV}$ through annealing, which implied a decrease of metallic electronic states in the materials. Furthermore, the $\mathrm{NiO}$ component (854.4 eV [37-39] for $\mathrm{Ni} 2 \mathrm{p}_{3 / 2}$ and $529.6 \mathrm{eV}$ [40-42] for $\mathrm{O} 1 \mathrm{~s}$ ) increased with annealing time. The molar ratio of $\mathrm{NiO} / \mathrm{Ni}(\mathrm{OH})_{2}$ was calculated from XPS to be approximately 0.10 and 0.31 in the samples annealed for 1 and $72 \mathrm{~h}$, respectively. The following dehydration reaction is suggested:

$\mathrm{Ni}(\mathrm{OH})_{2} \rightarrow \mathrm{NiO}+\mathrm{H}_{2} \mathrm{O}(5)$

It is known that $\mathrm{Ni}(\mathrm{OH})_{2}$ dehydrates at temperature greater than $523 \mathrm{~K}[23,34]$. Thus, in the CNT/Ni nanocomposite annealed at $T<473 \mathrm{~K}$, the only active Ni species is likely to be $\mathrm{Ni}(\mathrm{OH})_{2}$, but when annealed at $T \geq 523 \mathrm{~K}$, some $\mathrm{NiO}$ states may become electrochemically active.

\subsection{Specific capacitance per mass of active Ni species}

The surface area of the active materials is an important factor affecting specific capacitance. We did not directly measure the surface area in this study, but performed a 
relative comparison of the number and type $\left(\mathrm{NiO}\right.$ and $\left.\mathrm{Ni}(\mathrm{OH})_{2}\right)$ of active sites in the materials. The ratio of measured charge to the total theoretical charge of the active materials is the fraction of nickel sites, involved in the faradaic reaction, $z$, and can be estimated from the specific capacitance of the nanocomposite film by the following equation [19],

$z=\frac{C_{\mathrm{Ni}} \Delta V}{F / M}$

where $\Delta V$ is the potential window, $0.4 \mathrm{~V}$ in this study, $M$ is the average molecular weight of active Ni species, $F$ is the Faraday constant, and $C_{\mathrm{Ni}}$ is the specific capacitance per mass of active $\mathrm{Ni}$ species $\left(\mathrm{NiO}\right.$ and $\left.\mathrm{Ni}(\mathrm{OH})_{2}\right)(\mathrm{F} / \mathrm{g}) . C_{\mathrm{Ni}}$ was calculated based on the compositional information from EDX spectroscopy and XPS.

Figure 8 shows the $z$ value for the CNT/Ni nanocomposites fabricated at $3 \mathrm{~A} / \mathrm{cm}^{2}$ with and without annealing at $523 \mathrm{~K}$. The $z$ values of the sample with $(T, t)=(523 \mathrm{~K}, 1$ h) were markedly higher than those of other samples. This suggests an increase in the number of Faradic reaction sites following annealing in air at $523 \mathrm{~K}$ for $1 \mathrm{~h}$. However, the $z$ values of the sample with $(T, t)=(523 \mathrm{~K}, 72 \mathrm{~h})$ were low and similar to those of the sample without annealing.

Effect of surface oxidation states of $\mathrm{Ni}$ in $\mathrm{Ni}$-based pseudocapacitors has been discussed in the previous studies [10,12,31]. Nam et al. [12] reported that $\mathrm{NiO}$ formation from $\mathrm{Ni}(\mathrm{OH})_{2}$ by heating at $573 \mathrm{~K}$ is beneficial for stable pseudocapacitive behavior at high scan rates. However, they also reported that redox reaction of $\mathrm{Ni}(\mathrm{OH})_{2}$ is responsible for the increased capacitance during repeated cyclic voltammetry. Wu and Hsieh [31] also showed that the surface area and electric conductivity of $\mathrm{NiO}$ was larger than that of $\mathrm{Ni}(\mathrm{OH})_{2}$. Thus the $\mathrm{NiO}$ formation due to dehydration of $\mathrm{Ni}(\mathrm{OH})_{2}$ during the annealing is likely to increase in specific capacitance, although the detailed mechanism 
is still in debate. In this study, the sample with $(T, t)=(523 \mathrm{~K}, 72 \mathrm{~h})$ showed lower $z$ values, despite featuring a higher $\mathrm{NiO}$ component at the surface compared with the sample with $(T, t)=(523 \mathrm{~K}, 1 \mathrm{~h})($ Fig. 7$)$. This was definitely attributed to the coarsened texture of active Ni deposits through prolonged (72 h) annealing (Fig. 2b). The reduced surface area of these Ni deposits resulted in deterioration of the specific capacitance. Thus, the finely dispersed structure of Ni nanoparticles with sub-10 nm diameters, rather than oxidation state of $\mathrm{Ni}$, critically determines the high capacitance of Ni-based pseudocapacitors.

We performed additional $\mathrm{CV}$ measurements at a scan rate of $1 \mathrm{mV} / \mathrm{s}$ to compare the specific capacitance of these materials with other supercapacitors composed of $\mathrm{Ni}$ species. Figure 9 shows the specific capacitance per mass of active $\mathrm{Ni}$ species ( $\mathrm{NiO}$ and $\left.\mathrm{Ni}(\mathrm{OH})_{2}\right)\left(C_{\mathrm{Ni}}\right.$, measured by $\left.\mathrm{CV}\right)$ of the $\mathrm{CNT} / \mathrm{NiO}_{x}(\mathrm{OH})_{y}$ nanocomposite fabricated at 3 $\mathrm{A} / \mathrm{cm}^{2}$ and annealed in air at $523 \mathrm{~K}$ for $1 \mathrm{~h}$, together with previous data from the literature $[10,12,13-15] . C_{\mathrm{Ni}}$ of capacitive electrodes generally decrease as the scan rate increases, as shown in Fig. 9. $C_{\mathrm{Ni}}$ of our $\mathrm{CNT} / \mathrm{Ni}$ nanocomposites were higher than those of graphene oxide/ $\mathrm{NiO}$ [13] and porous $\mathrm{NiO}$ [14] and comparable with those of other $\mathrm{CNT} / \mathrm{NiO}_{x}$ composites $[10,12,15]$. This comparison suggests that $\mathrm{CNT}$ are effective for fast electron transfer in the CNT/Ni nanocomposite electrode.

Figure 10 shows $C_{\mathrm{Ni}}$ (measured by $\mathrm{CP}$ ) of the $\mathrm{CNT} / \mathrm{Ni}$ nanocomposite fabricated at 3 $\mathrm{A} / \mathrm{cm}^{2}$ and annealed in air at $523 \mathrm{~K}$ for $1 \mathrm{~h}$. The maximum $C_{\mathrm{Ni}}$ was $1259 \mathrm{~F} / \mathrm{g}$ at the a discharge current of $5.6 \mathrm{~A} / \mathrm{g}$, which is also comparable with $C_{\mathrm{Ni}}$ measured by $\mathrm{CP}$ in the previous studies $[13,14,16,18,24]$. 


\section{Conclusions}

In this study, $\mathrm{CNT} / \mathrm{NiO}_{x}(\mathrm{OH})_{y}$ nanocomposite films were synthesized by EPD of CNTs, the pulsed electrodeposition of Ni, followed by annealing steps. The materials were tested as electrochemical capacitors. Small $(7 \mathrm{~nm}) \mathrm{Ni}$ nanoparticles were uniformly deposited on the CNT surfaces by EPD. After annealing in air at $523 \mathrm{~K}$ for 1 h, specific capacitance per mass of active Ni species were measured as high as $1451 \mathrm{~F} / \mathrm{g}$ at a scan rate of $1 \mathrm{mV} / \mathrm{s}$. SEM images and XPS analyses of the samples revealed that $\mathrm{NiO}$ formation from dehydration of $\mathrm{Ni}(\mathrm{OH})_{2}$ during annealing at $523 \mathrm{~K}$ was beneficial for the capacitance, but that long annealing times ( $72 \mathrm{~h}$ in this study) produced coarse, aggregated $\mathrm{Ni}$ deposits with decreased specific capacitance. In cyclic $\mathrm{CP}$ tests, the specific capacitance was maintained over 20,000 cycles at $138.9 \mathrm{~A} / \mathrm{g}$, which implied excellent durability. These results suggest that this porous structured $\mathrm{CNT} / \mathrm{NiO}_{x}(\mathrm{OH})_{y}$ nanocomposite is a promising material for supercapacitors.

\section{Acknowledgments}

Capacitance measurements were financially supported by a JSPS Grant-in-Aid for Challenging Exploratory Research 25630303. M. H. thanks The Iwatani Naoji Foundation for supporting the synthesis of samples. The authors also thank Prof. T. Yao and Prof. T. Yabutsuka (Kyoto Univ., Japan) for their cooperation in SEM observations.

\section{References}

[1] S. Iijima, Nature 354 (1991) 56-58.

[2] L. Hu, D. S. Hecht, G. Grüner, Chem. Rev. 110 (2010) 5790-5844.

[3] A. R. Boccaccini, J. Cho, J. A. Roether, B. J. C. Thomas, E. J. Minay, M. S. P. 
Shaffer, Carbon 44 (2006) 3149-3160.

[4] S.-M. Bak, K.-H. Kim, C.-W. Lee, K.-B. Kim, J. Mater. Chem. 21 (2011) 1984-1990.

[5] K.-Y. Lin, W.-T. Tsai, J.-K. Chang, Int. J. Hydrogen Energy 35 (2010) 7555-7562.

[6] C.-Y. Chen, K.-Y. Lin, W.-T. Tsai, J-K. Chang, C.-M. Tseng, Int. J. Hydrogen Energy 35 (2010) 5490-5497.

[7] Z. Liu, Z. Li, F. Wang, J. Liu, J. Ji, K. C. Park, M. Endo, Mater. Res. Bull. 47 (2012) $338-343$.

[8] C.-T. Hsieh, Y.-W. Chou, W.-Y. Chen, J. Solid State Electrochem. 12 (2008) $663-669$.

[9] B. Gao, C.-Z. Yuan, L.-H. Su, L. Chen, X.-G. Zhang, J. Solid State Electrochem. 13 (2009) 1251-1257.

[10] B. Wen, S. Zhang, H. Fang, W. Liu, Z. Du, Mater. Chem. Phys. 131 (2011) 8-11.

[11] J. Y. Lee, K. Liang, K. H. An, Y. H. Lee, Synth. Metals 150 (2005) 153-157.

[12] K.-W. Nam, K.-H. Kim, E.-S. Lee, W.-S. Yoon, X.-Q. Yang, K.-B. Kim, J. Power Sources 182, (2008) 642-652.

[13] X. Zhu, H. Dai, J. Hu, L. Ding, L. Jiang J. Power Sources 203 (2012) 243-249.

[14] K. Liang, X. Tang, W. Hu, J. Mater. Chem. 22 (2012) 11062-11067.

[15] K.-W. Nam, E.-S. Lee, J.-H. Kim, Y.-H. Lee, K.-B. Kim, J. Electrochem. Soc. 152 (2005) A2123-A2129.

[16] C. Yuan, J. Li, L. Hou, L. Yang, L. Shen, X. Zhang, Electrochim. Acta 78 (2012) $532-538$.

[17] Q. Lu, M. W. Lattanzi, Y. Chen, X. Kou, W. Li, X. Fan, K. M. Unruh, J. G. Chen, J. Q. Xiao, Angew. Chem. 123 (2011) 6979-6982 
[18] M. Yang, J. X. Li, H. H. Li, L. W. Su, J. P. Wei, Z. Zhou, Phys. Chem. Chem. Phys. 14 (2012) 11048-11052.

[19] K.-W. Nam, K.-B. Kim, J. Electrochem. Soc. 149 (2002) A346-A354.

[20] A. G. Pandolfo, A. F. Hollenkamp, J. Power Sources 157 (2006) 11-27.

[21] Y.-G. Wang, X.-G. Zhang, Electrochim. Acta 49 (2004) 1957-1962.

[22] C.-C. Hu, M.-J. Liu, K.-H. Chang, J. Power Sources 163 (2007) 1126-1131.

[23] S. Chen, J. Zhu, X. Wu, Q. Han, X. Wang, ACS Nano 4 (2010) 2822-2830.

[24] D.-S. Kong, J.-M. Wang, H.-B. Shao, J.-Q. Zhang, C.-N. Cao, J. Alloy. Compd. 509 (2011) 5611-5616.

[25] Y. I. Golovin, D. Y. Golovin, A. V. Shuklinov, R. A. Stolyarov, V. M. Vasyukov, Tech. Phys. Lett. 37 (2011) 253-255.

[26] Z.-C. Wang, Z.-B. Qi, Q.-H. Liao, in: Proceedings of 2nd IEEE International Nanoelectronics Conference (INEC 2008), IEEE, 2008, pp. 539-541.

[27] N. Chopra, W. Shi, A. Bansal, Carbon 49 (2011) 3645-3662.

[28] N. Chopra, H. G. McWhinney, W. Shi, Mater. Charact. 62 (2011) 635-641.

[29] H. Natter, R. Hempelmann, Electrochim. Acta 49 (2003) 51-61.

[30] H. Natter, M. Schmelzer, R. Hempelmann, J. Mater. Res. 13 (1998) 1186-1197.

[31] M. S. Wu, H. H. Hsieh, Electrochim. Acta 53 (2008) 3427-3435.

[32] B. P. Löchel, H.-H. Strehblow, J. Electrochem. Soc. 131 (1984) 713-723.

[33] J. C. Klein, D. M. Hercules, J. Catal. 82 (1983) 424-441.

[34] P.-H. Lo, W.-T. Tsai, J.-T. Lee, M.-P. Hung, J. Electrochem. Soc. 142 (1995) 91-96.

[35] J. Haber, J. Stoch, L. Ungier, J. Electron Spectrosc. Relat. Phenom. 9 (1976) $459-467$.

[36] A. N. Mansour, Surf. Sci. Spectra 3 (1994) 221-230. 
[37] A. N. Mansour, Surf. Sci. Spectra 3 (1994) 231-238.

[38] K. Kishi, J. Electron Spectrosc. Relat. Phenom. 46 (1988) 237-247.

[39] R. B. Shalvoy, P. J. Reucroft, B. H. Davis, J. Catal. 56 (1979) 336-348.

[40] M. Oku, H. Tokuda, K. Hirokawa, J. Electron Spectrosc. Relat. Phenom. 53 (1991) 201-211.

[41] A. R. González-Elipe, R. Alvarez, J. P. Holgado, J. P. Espinos, G. Munuera, J. M. Sanz, Appl. Surf. Sci. 51 (1991) 19-26.

[42] P. H. Bolt, E. ten Grotenhuis, J. W. Geus, F. H. P. M. Habraken, Surf. Sci. 329 (1995) 227-240.

[43] W. Xing, F. Li, Z.-F. Yang, G. Q. Lu, J. Power Sources 134 (2004) 324-330.

Figure captions

Figure 1. SEM images of (a) electrophoretically deposited CNTs prior to pulsed electrodeposition of $\mathrm{Ni}$, (b) CNT/Ni nanocomposite fabricated by pulsed electrodeposition of $\mathrm{Ni}$ at $0.03 \mathrm{~A} / \mathrm{cm}^{2}$, (c) CNT/Ni nanocomposite fabricated by pulsed electrodeposition of $\mathrm{Ni}$ at $3 \mathrm{~A} / \mathrm{cm}^{2}$.

Figure 2. SEM images of $\mathrm{CNT} / \mathrm{NiO}_{x}(\mathrm{OH})_{y}$ nanocomposite fabricated by pulsed electrodeposition of $\mathrm{Ni}$ at $3 \mathrm{~A} / \mathrm{cm}^{2}$ and annealed in air at $523 \mathrm{~K}$ for (a) 1 and (b) $72 \mathrm{~h}$.

Figure 3. $\mathrm{CV}$ curves of $\mathrm{CNT} / \mathrm{NiO}_{x}(\mathrm{OH})_{y}$ nanocomposite fabricated by pulsed electrodeposition at $3 \mathrm{~A} / \mathrm{cm}^{2}$ and annealed in air at $523 \mathrm{~K}$ for $1 \mathrm{~h}$. Scan rates of 10,30 , $50,100 \mathrm{mV} / \mathrm{s}$ as indicated.

Figure 4. Relationship between specific capacitance per mass of $\mathrm{CNT} / \mathrm{NiO}_{x}(\mathrm{OH})_{y}$ nanocomposite and scan rate. Effects of (a) maximum current density during pulsed electrodeposition of $\mathrm{Ni}$, (b) annealing conditions, (c) annealing temperature and (d) 
annealing time are shown.

Figure 5. Galvanostatic discharge curves of the $\mathrm{CNT} / \mathrm{NiO}_{x}(\mathrm{OH})_{y}$ nanocomposite fabricated by pulsed electrodeposition at $3 \mathrm{~A} / \mathrm{cm}^{2}$ and annealed in air at $523 \mathrm{~K}$ for $1 \mathrm{~h}$.

Figure 6. 20000-cycle charge-discharge test result of CNT/Ni nanocomposite fabricated at maximum current density of $3 \mathrm{~A} / \mathrm{cm}^{2}$ and annealed in air at $523 \mathrm{~K}$ for $1 \mathrm{~h}$. Discharge current was set to $138.9 \mathrm{~A} / \mathrm{g}$. Galvanostatic charge/discharge curves of initial and final $4 \mathrm{~s}$ are shown in inset.

Figure 7. X-ray photoelectron spectra of CNT/Ni nanocomposites fabricated at $3 \mathrm{~A} / \mathrm{cm}^{2}$ with and without subsequent annealing for oxidation of $\mathrm{Ni}$. (a) $\mathrm{Ni} 2 \mathrm{p}_{3 / 2}$, (b) $\mathrm{O} 1 \mathrm{~s}$ and (c) valence band.

Figure 8. Fraction of $\mathrm{Ni}$ sites involved in Faradaic reaction of the CNT/Ni nanocomposite fabricated by pulsed electrodeposition of $\mathrm{Ni}$ at $3 \mathrm{~A} / \mathrm{cm}^{2}$ with and without annealing at $523 \mathrm{~K}$ as a function of scan rate in $\mathrm{CV}$ measurement.

Figure 9. Relationship between specific capacitances (measured by cyclic voltammetry) of Ni-species supercapacitors per mass of active $\mathrm{Ni}$ species and scan rate. The present results of $\mathrm{CNT} / \mathrm{NiO}_{x}(\mathrm{OH})_{y}$ nanocomposite fabricated at $3 \mathrm{~A} / \mathrm{cm}^{2}$ and annealed in air at $523 \mathrm{~K}$ for $1 \mathrm{~h}$ are also shown.

Figure 10. Relationship between specific capacitances (measured by chronopotentiometry) of Ni-species supercapacitors per mass of active $\mathrm{Ni}$ species and discharge current. The present results of $\mathrm{CNT} / \mathrm{NiO}_{x}(\mathrm{OH})_{y}$ nanocomposite fabricated at 3 $\mathrm{A} / \mathrm{cm}^{2}$ and annealed in air at $523 \mathrm{~K}$ for $1 \mathrm{~h}$ are also shown. 

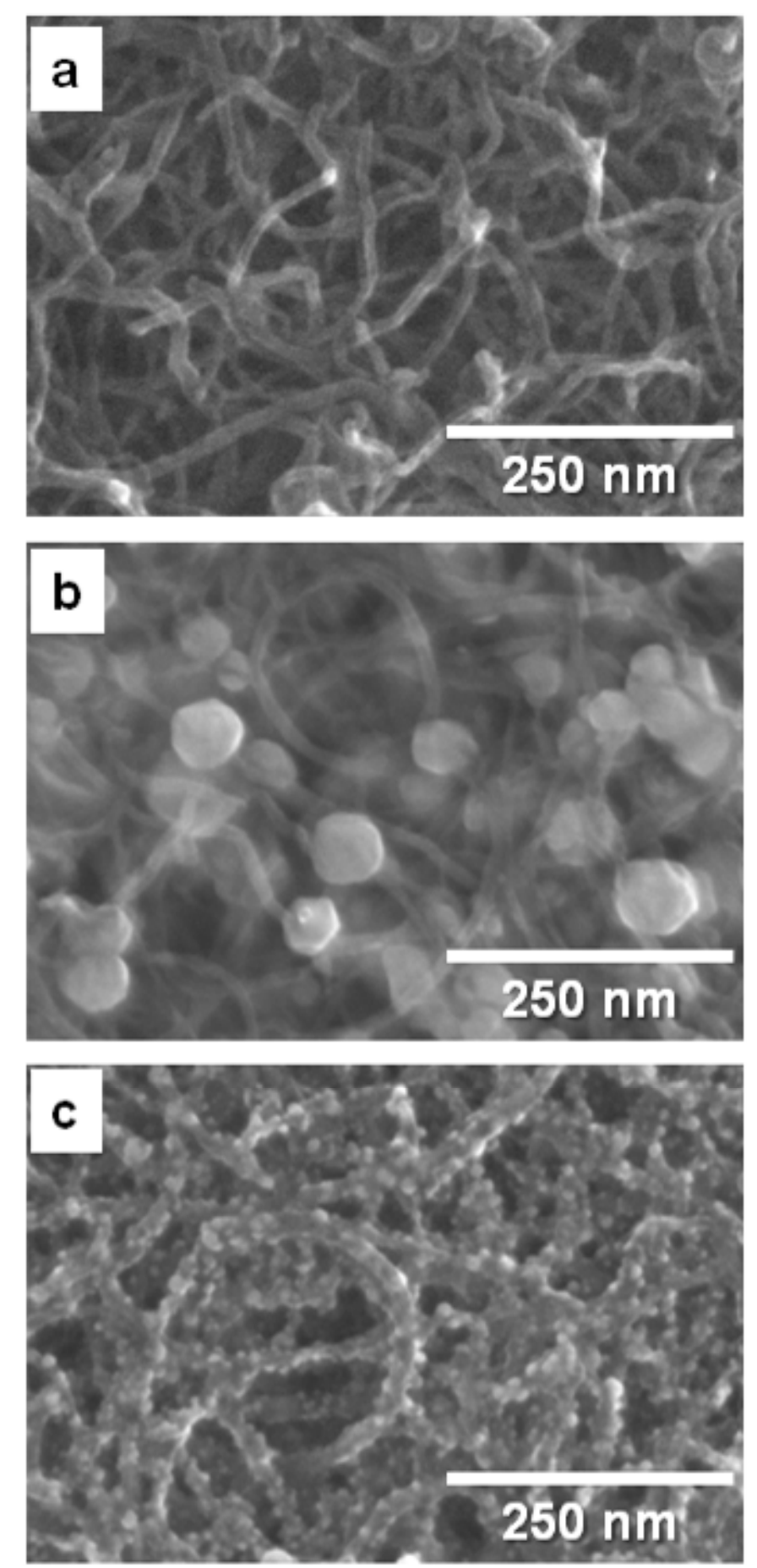

Figure 1. 

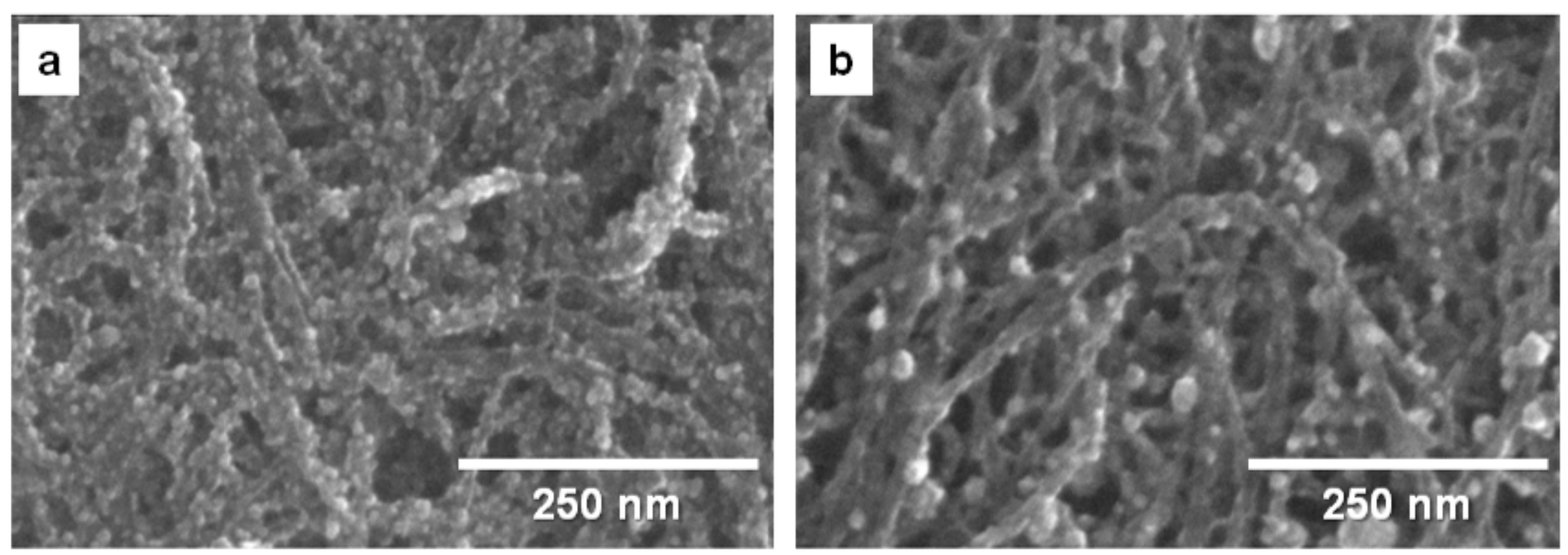

Figure 2. 


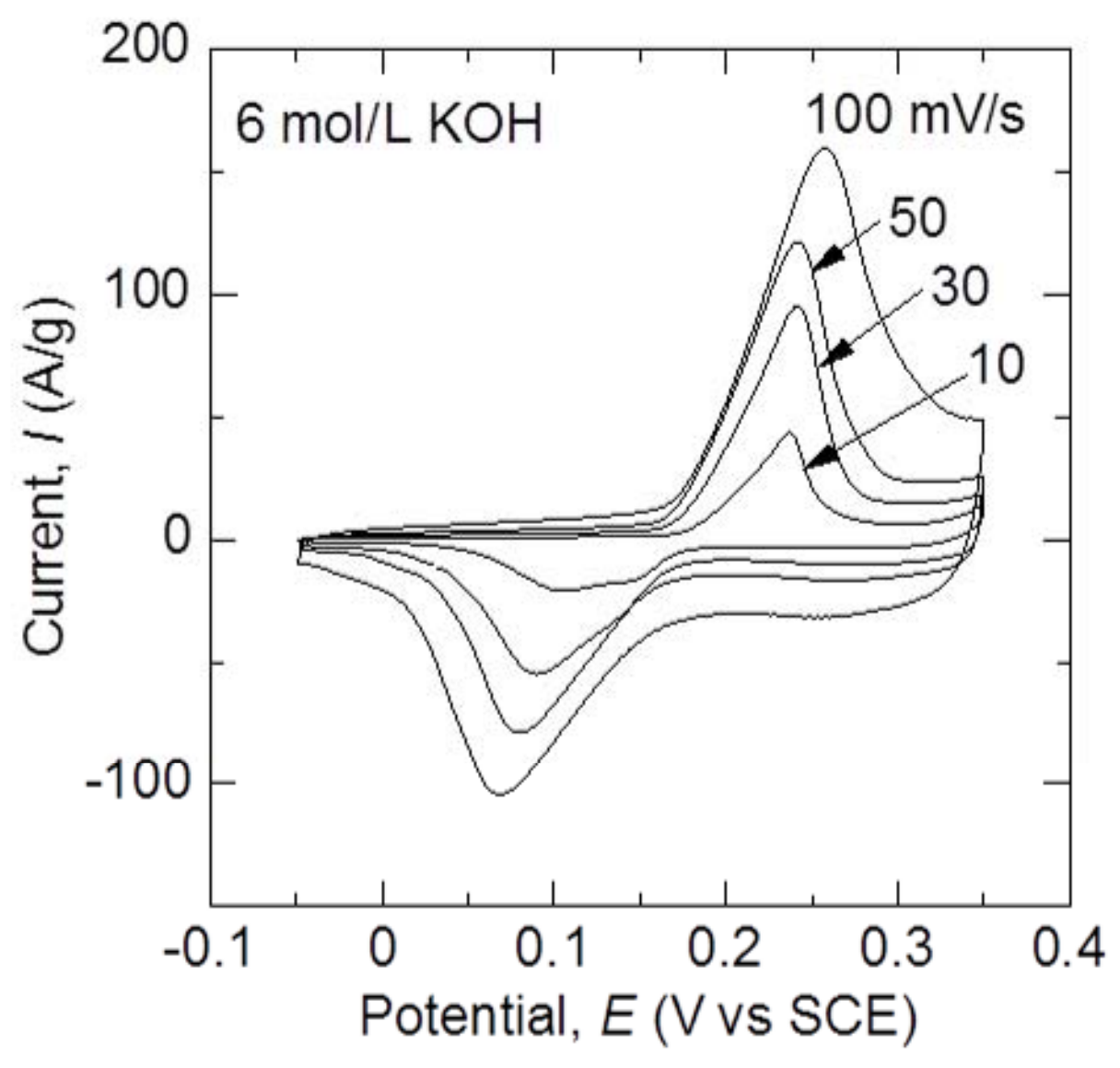

Figure 3. 


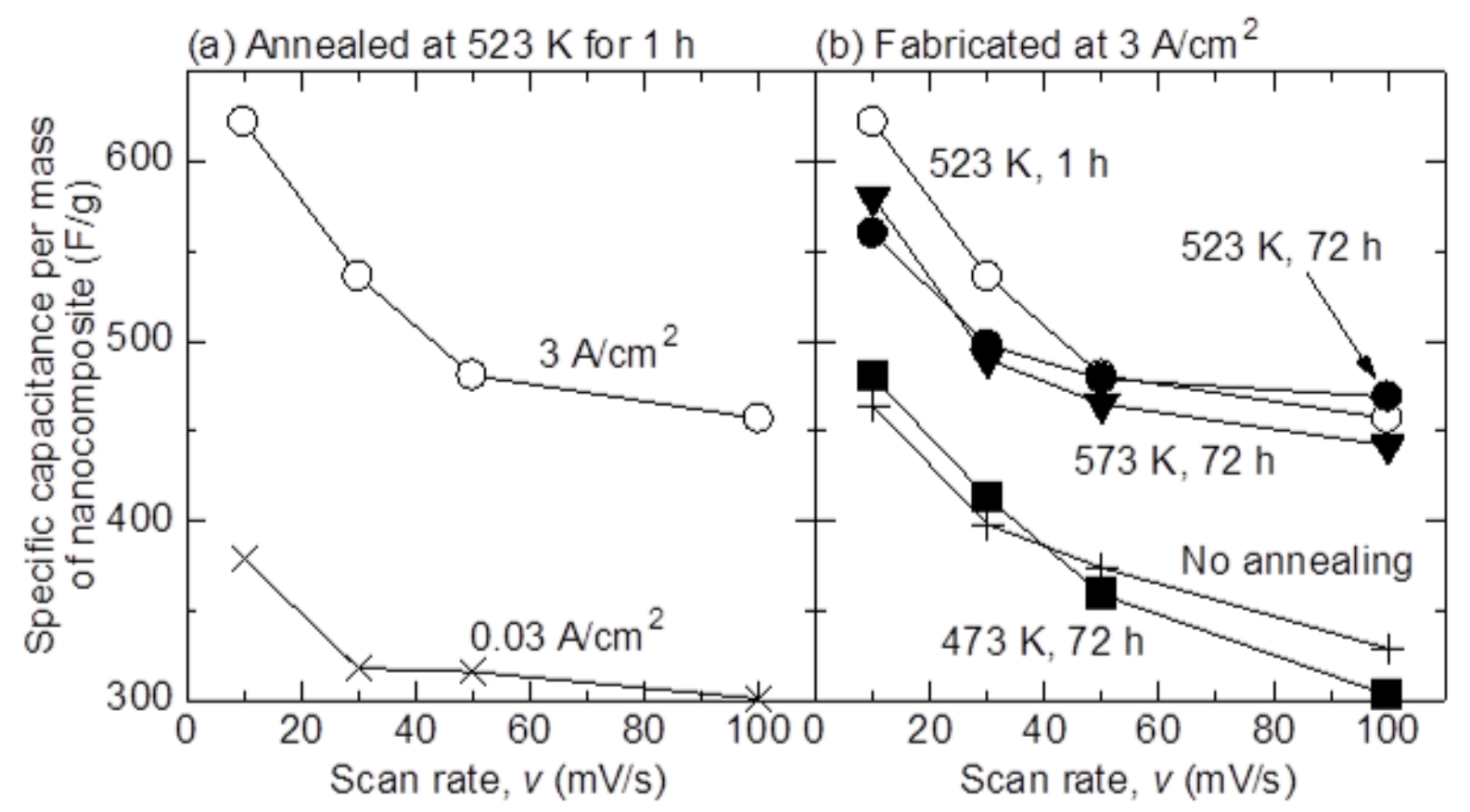

Figure 4.

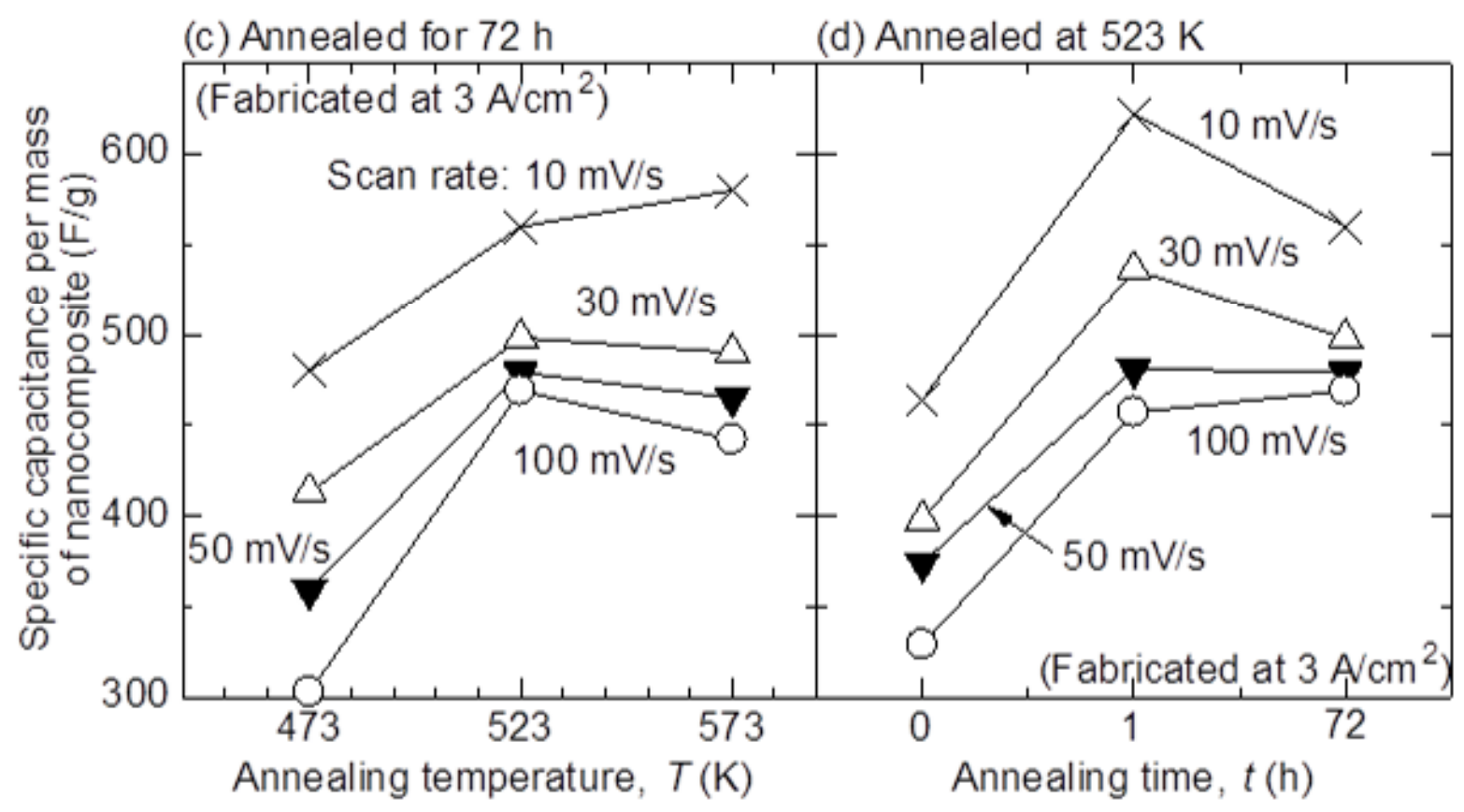




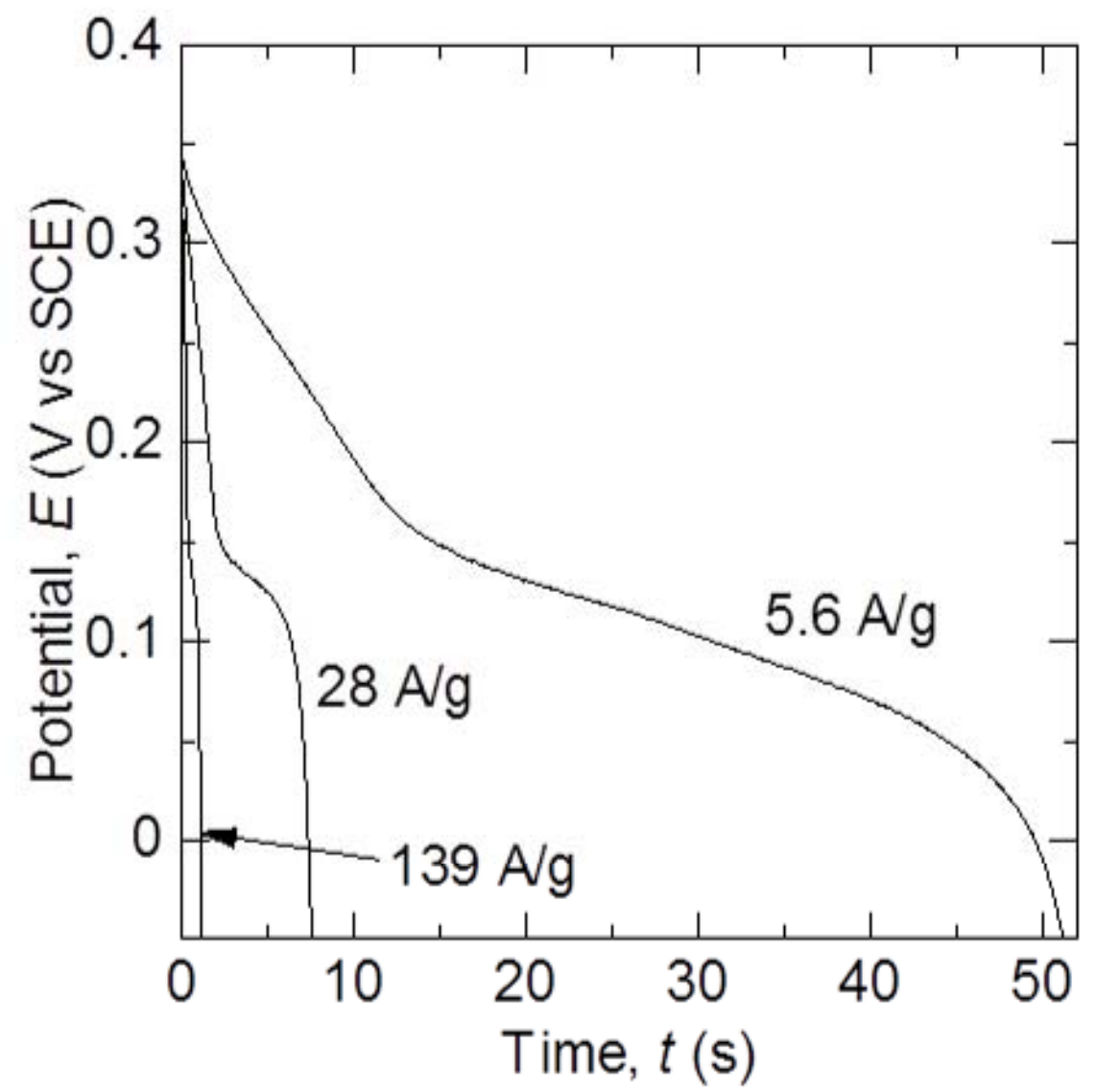

Figure 5. 


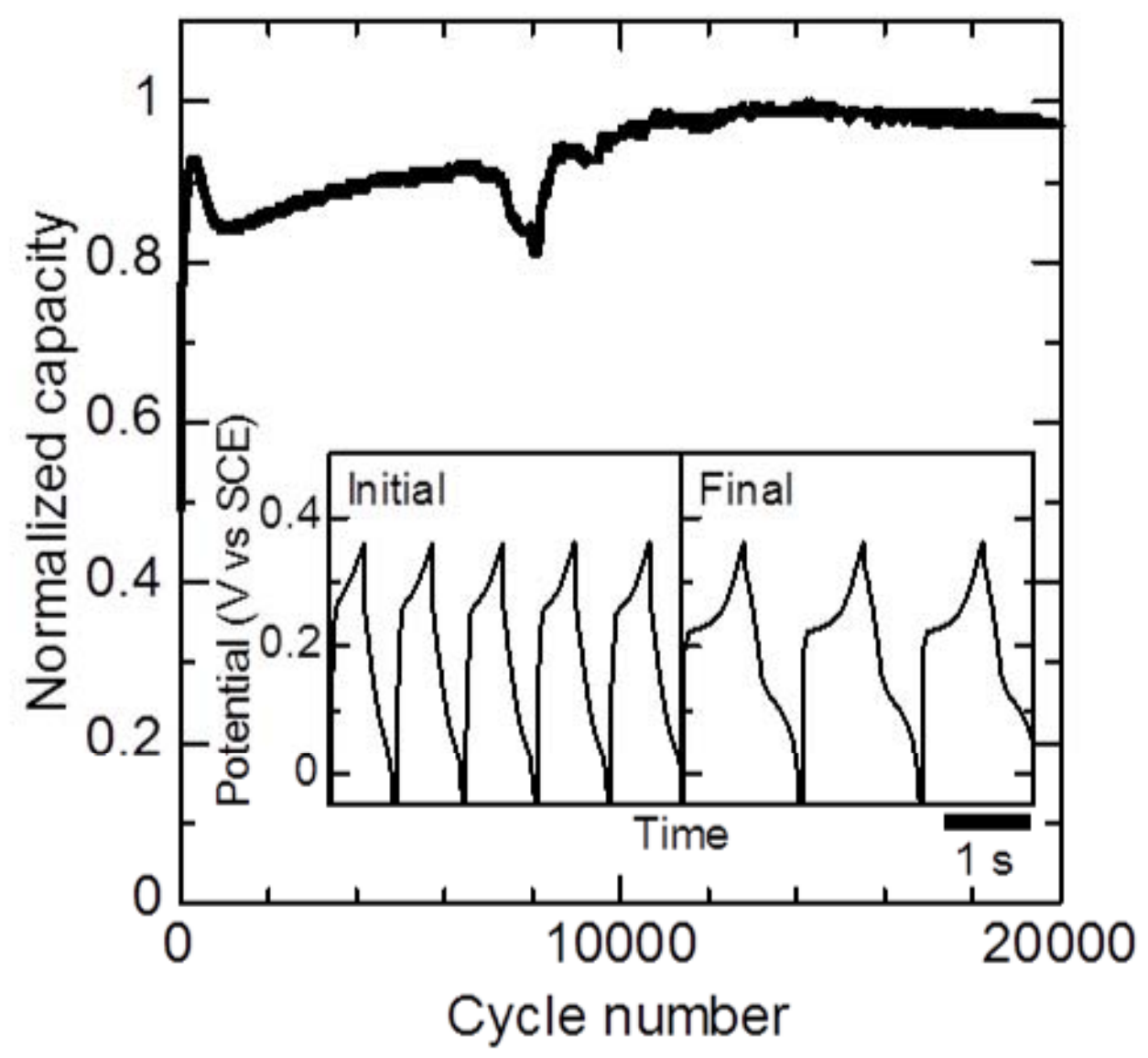

Figure 6. 

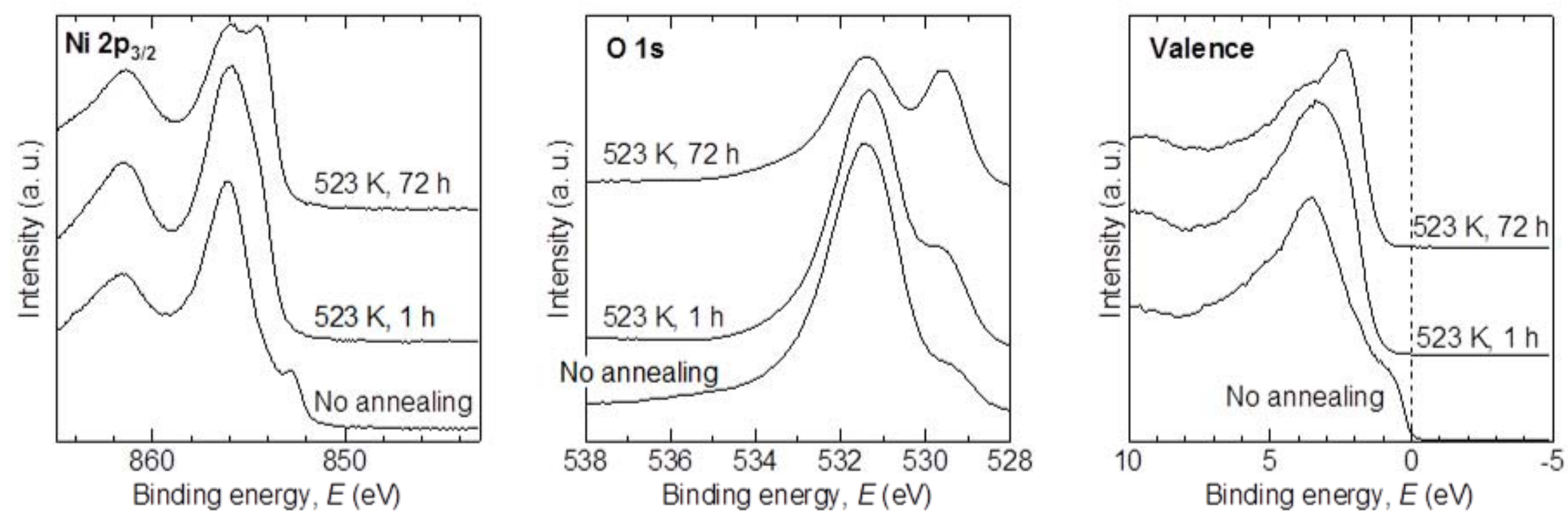

Figure 7. 


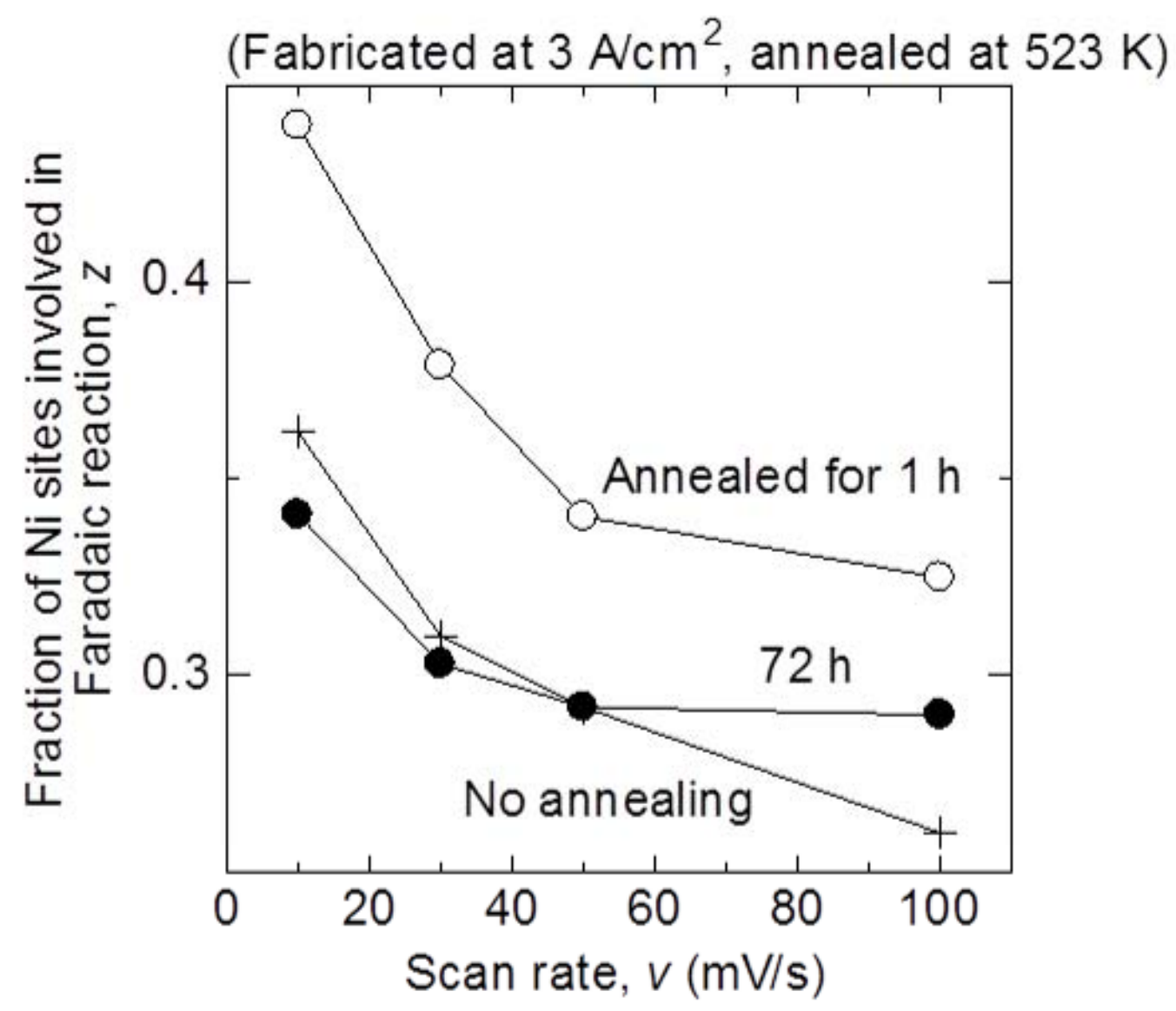

Figure 8. 


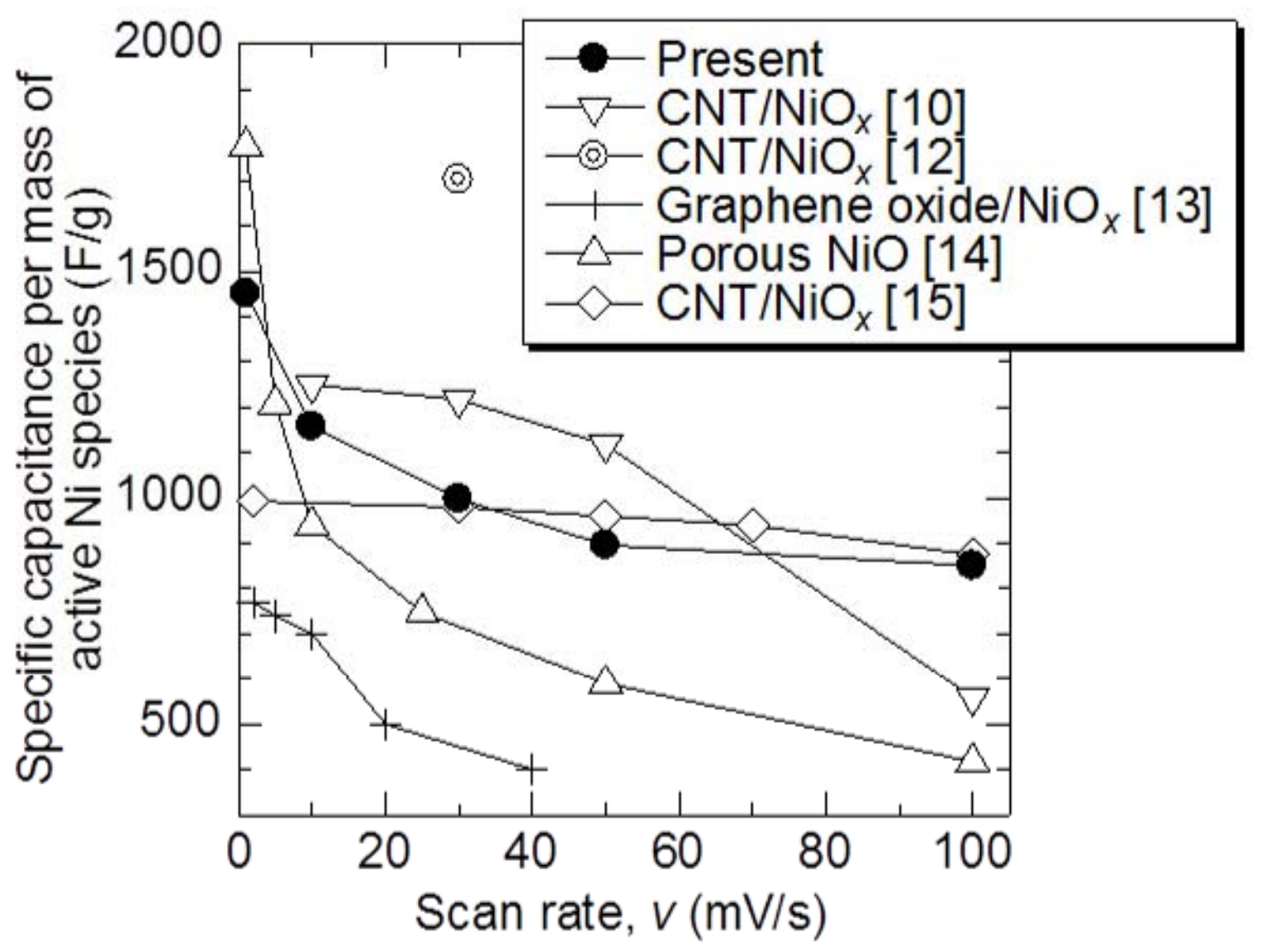




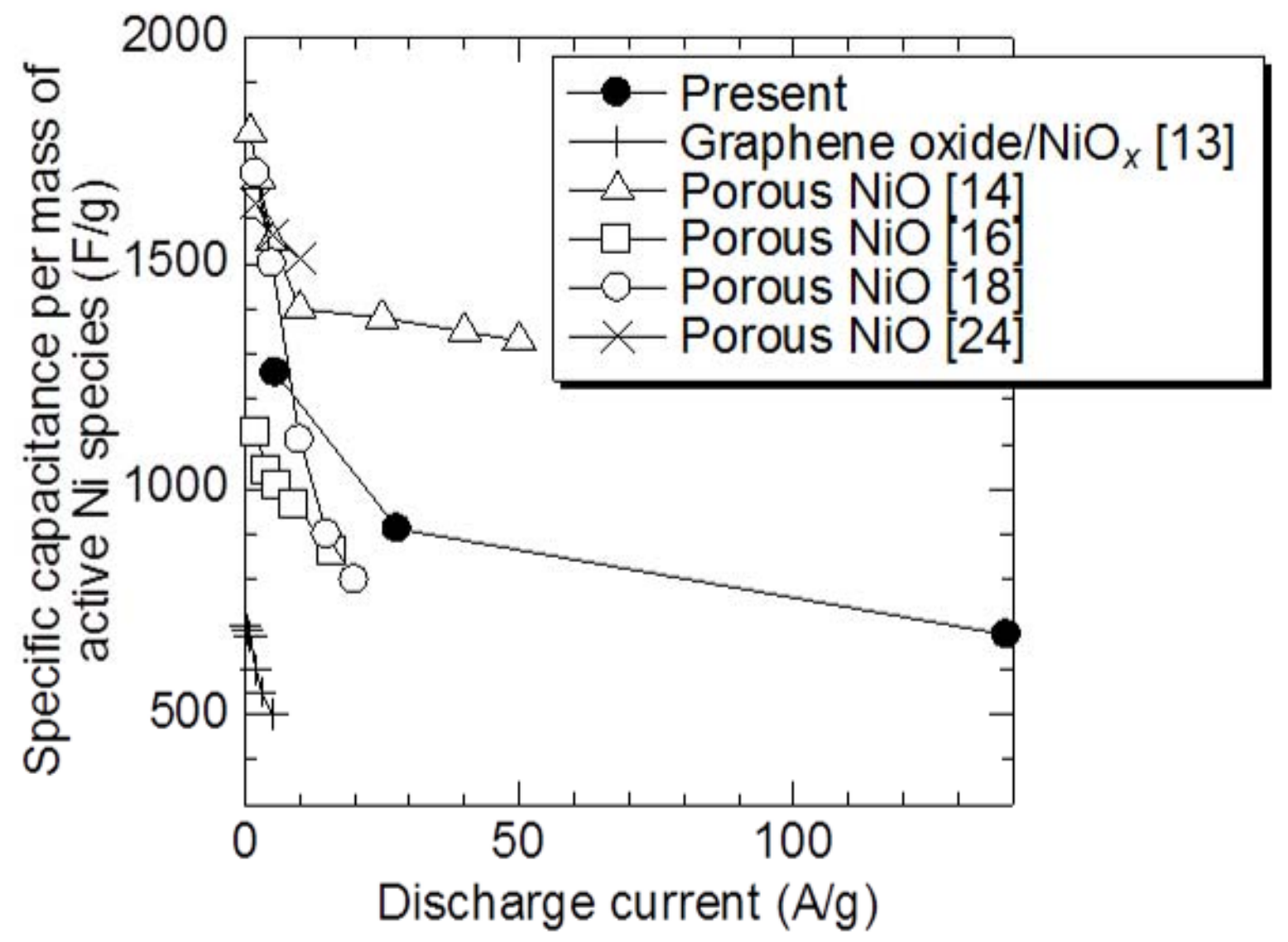

